Article

\title{
A Fuzzy Multicriteria Decision-Making (MCDM) Model for Sustainable Supplier Evaluation and Selection Based on Triple Bottom Line Approaches in the Garment Industry
}

\author{
Chia-Nan Wang ${ }^{1, *}$, Ching-Yu Yang ${ }^{2}$ and Hung-Chun Cheng ${ }^{1,3, *}$ \\ 1 Department of Industrial Engineering and Management, National Kaohsiung University of Science and \\ Technology, Kaohsiung 80778, Taiwan \\ 2 Department of Mold and Die Engineering, National Kaohsiung University of Science and Technology, \\ Kaohsiung 80778, Taiwan \\ 3 Hung Chun Bio-S Co., LTD., Kaohsiung 80778, Taiwan \\ * Correspondence: cn.wang@newfancy.com (C.-N.W.); hungchuncheng2018@gmail.com (H.-C.C.)
}

Received: 7 May 2019; Accepted: 21 June 2019; Published: 27 June 2019

check for

\begin{abstract}
Vietnam's garment industry is facing many challenges, including domestic competition and the global market. The free trade agreement, which Vietnam signed, includes environmental barriers, sustainable development, and green development. The agreement further requires businesses to make efforts to improve not only product quality but also the production process. In cases when enterprises cause environmental pollution in the production process and do not apply solutions to reduce waste, save energy, and natural resources, there is a risk of no longer receiving orders or orders being rejected, especially orders from the world's major branded garment companies. In this research, the authors propose a multicriteria decision-making model (MCDM) for optimizing the supplier evaluation and selection process for the garment industry using sustainability considerations. In the first stage of this research, all criteria affecting supplier selection are determined by a triple bottom line (TBL) model (economic, environmental, and social aspects) and literature reviews; in addition, the fuzzy analytic hierarchy process (FAHP) method was utilized to identify the weight of all criteria in the second stage. The technique for order preference by similarity to an ideal solution (TOPSIS) is a multicriteria decision analysis method, which is used for ranking potential suppliers in the final stage. As a result, decision-making unit 10 (DMU/10) is found to be the best supplier for the garment industry. The contribution of this research includes modeling the supplier selection decision problem based on the TBL concept. The proposed model also addresses different complex problems in supplier selection, is a flexible design model for considering the evaluation criteria, and is applicable to supplier selection in other industries.
\end{abstract}

Keywords: garment industry; optimization; supplier selection; fuzzy logics; FAHP; triple bottom line; TOPSIS

\section{Introduction}

Vietnam's garment industry is experiencing a high growth rate. Furthermore, the number of related companies has continued to increase over the years, and the industry size is gaining in all resources [1]. The target is a large domestic market with more than 86 million people and potential customers in the garment industry [1]. Recently, the textile and garment industry has experienced a good growth rate; exports in 2017 were over USD 31 billion, up more than 10\% compared with those of the previous year [1]. Although the garment industry has a sustainable economic development, it is 
a threat to the environment and to social welfare, owing to problems like pollution, waste, human rights issues, etc. [2]. Therefore, achieving sustainability in garment business operations must involve considering more than just economic development.

In fact, sustainable development has different meanings to different people. The term "sustainable development" first appeared in 1980, in the publication of the World Conservation Strategy, with the simple content "The development of humanity can not only focus on economic development but also respect the essential needs of society and the impact on the ecological environment" [3]. In addition, the World Commission on Environment and Development defined sustainable development, stating "Sustainable development is a new type of development, integrating the production process with resource conservation and environmental quality improvement. Sustainable development must meet the demand of the current generation without compromising their ability to meet the demand of future generations" [4]. Thus, to achieve these objectives, enterprises must focus on many factors, including $\mathrm{CO}_{2}$ and toxic emissions, energy use and efficiency, waste generation, and employee health and safety [3].

In order to achieve sustainable production in operations, sustainability needs to be considered at all stages of the garment supply chain. In supply chain management, sustainable suppliers are of great importance in an enterprise's business operations [5]. Thus, it requires enterprises to have an abundant and stable supply of raw materials, ensuring that production schedules are met. Suppliers must also ensure the supply of green materials in terms of quantity, quality, stability, and accuracy to meet the requirements of production and business, with low costs and delivery times [5]. Thus, choosing a good supplier and managing the supplier is a prerequisite for helping organizations produce products of the right quality, according to prescribed schedules, with reasonable prices and competitive ability. Therefore, creating a supplier evaluation and selection process with sustainability considerations is a necessary activity. Furthermore, it is among the prerequisites that help businesses to develop sustainability. Multi-criteria decision making (MCDM) is a discipline in its own right, which deals with decisions involving the choice of a best alternative from several potential candidates in a decision, subject to several criteria that may be concrete or vague [6]. Sustainable supplier selection involves multicriteria decision-making (MCDM); thus, the decision-maker has to consider and evaluate qualitative and quantitative factors.

In this research, the authors propose a multicriteria decision-making model (MCDM) approach for optimizing the supplier evaluation and selection process for the garment industry using sustainability considerations. In the first stage of this research, all criteria affecting location selection are determined by the triple bottom line (TBL) model (economic, environmental, and social aspects) and literature reviews. In addition, the fuzzy analytic hierarchy process (FAHP) method was utilized to identify the weight of all criteria in the second stage. The technique for order preference by similarity to an ideal solution (TOPSIS) is a multicriteria decision analysis method, which is used for ranking potential suppliers in the final stage.

The remainder of the article introduces a literature review to assist in developing the fuzzy MCDM model. Then, a hybrid model using FAHP and TOPSIS is shown to select the best sustainable suppliers in garment industry. The discussion and results are presented at the end of this paper.

\section{Literature Review}

A sustainable supplier selection process is crucial in a globalized competitive environment to support a sustainable development business. The purpose of choosing the right supplier is to increase customer satisfaction, improve competitiveness, and minimize production costs. In the literature, there is much research analyzing the garment industry's impacts on the environment [7]. Baskaran et al. [8] applied a grey model for analyzing Indian textile suppliers' sustainability evaluations. The results indicate that the criterion of long working hours is a critical one for both categories of suppliers; in the case of garment manufacturers, they found that pollution and unfair competition were the most important criteria. In addition, employing child labor was found to be a critical criterion 
in the case of ancillary suppliers. Lo et al. [9] presented empirical evidence on the performance impact of the adoption of environmental management systems in the fashion and textiles related industries (FTIs). Although environmental management systems (EMSs) have emerged as a passport to business in FTIs, their actual impacts on firms' financial performances have not been explored.

Turker et al. [10] analyzed supply chain management (SCM) with sustainability considerations in the fast fashion industry. The results of the study reveal that these companies focus significantly on supplier compliance with their code of conduct, employing further monitoring and auditing activities to prevent production problems in developing countries, improve overall supply chain performance, and set sustainability criteria for their suppliers. Goninan et al. [11] applied an MCDM model to measure the sustainability performance of a supplier based on the triple bottom line (TBL) approach. In this research, the authors used triangular fuzzy numbers to express linguistic values of experts' subjective preferences. Qualitative performance evaluation is performed by using fuzzy numbers to find criteria weights, and then fuzzy TOPSIS is proposed for finding the ranking of suppliers. Wittstruck et al. [12] proposed a hybrid model using a fuzzy-analytic hierarchy process (AHP)-TOPSIS approach for sustainability partner selection. The goal of this paper is developing an integrated MCDM model that supports recycling partners. Büyüközkan et al. [13] proposed a novel hybrid MCDM approach based on fuzzy decision-making trial and evaluation laboratory (DEMATEL), fuzzy analytical network process (FANP), and fuzzy TOPSIS to evaluate green suppliers. This paper examines green supply chain management (GSCM) and GSCM capability dimensions to propose an evaluation framework for green suppliers.

Kannan et al. [14] introduced a hybrid model using fuzzy TOPSIS to select green suppliers. Results of this study indicate that the four dominant criteria are commitment of senior management to GSCM; product designs that reduce, reuse, recycle, or reclaim materials, components, or energy; compliance with legal environmental requirements and auditing programs; and product designs that avoid or reduce toxic or hazardous material use. Kannan et al. [15] integrated fuzzy MCDM and a multi-objective programming model for supplier selection in a green supply chain. The objective of their model is to simultaneously maximize the total value of purchasing and to minimize the total cost of purchasing. Wang et al. [16] used a fuzzy TOPSIS approach to assess improvement areas when implementing green supply chain initiatives. An illustrative case is presented to help researchers and practitioners understand the importance of developing an appropriate organization strategy for implementing green practices. Wang et al. [17] generalized TOPSIS to fuzzy multiple-criteria group decision-making (FMCGDM) in a fuzzy environment. In this work, the authors proposed two operators, Up and Lo, which satisfy the partial ordering relation on fuzzy numbers to the generalization of TOPSIS.

Mani et al. [18] focused on socially sustainable supplier selection through social parameters by using the AHP in decision making. This research supports supply chain managers integrating various social dimensions into the supply chain function. Rouyendegh et al. [19] applied an AHP model for supplier selection. The authors applied multicriteria analysis for cost, flexibility, quality, delivery, and variety. The present report provides an accurate and easy classification of supplier attributes that have been prioritized in the model. Grover et al. [20] proposed an MCDM model by using AHP and TOPSIS for supplier selection using sustainable criteria. The purpose of this study is to maximize supply chain profitability, maximize the social wellbeing of the supply chain, and minimize environmental impacts.

Based on the opinion of experts and the literature review, there are three main factors that have to considered in the fabric supplier selection process, namely economic, social, and environmental factors. There are many researchers who have applied the MCDM model to various fields of science and engineering, a trend that has been increasing for many years, but very few works have focused on this problem in a fuzzy environment. This is a reason why in this research, the authors propose a multicriteria decision-making model (MCDM) for optimizing the supplier evaluation and selection process in the garment industry using sustainability considerations under fuzzy environment conditions. 


\section{Methodology}

\subsection{Research Development}

In this research, the authors propose an MCDM model for sustainable supplier evaluation and selection in the garment industry, based on the TBL approach. There are three main steps in this research, as shown in Figure 1.

Step 1: All of the criteria and sub-criteria effects on sustainable supplier evaluation and selection are defined based on the TBL approach and literature reviews.

Step 2: The fuzzy analytic hierarchy process (FAHP) method is utilized to identify the weight of all criteria in the second stage.

Step 3: The technique for order of preference by similarity to an ideal solution (TOPSIS) is an MCDM method, which is applied for ranking potential suppliers in the final stage.

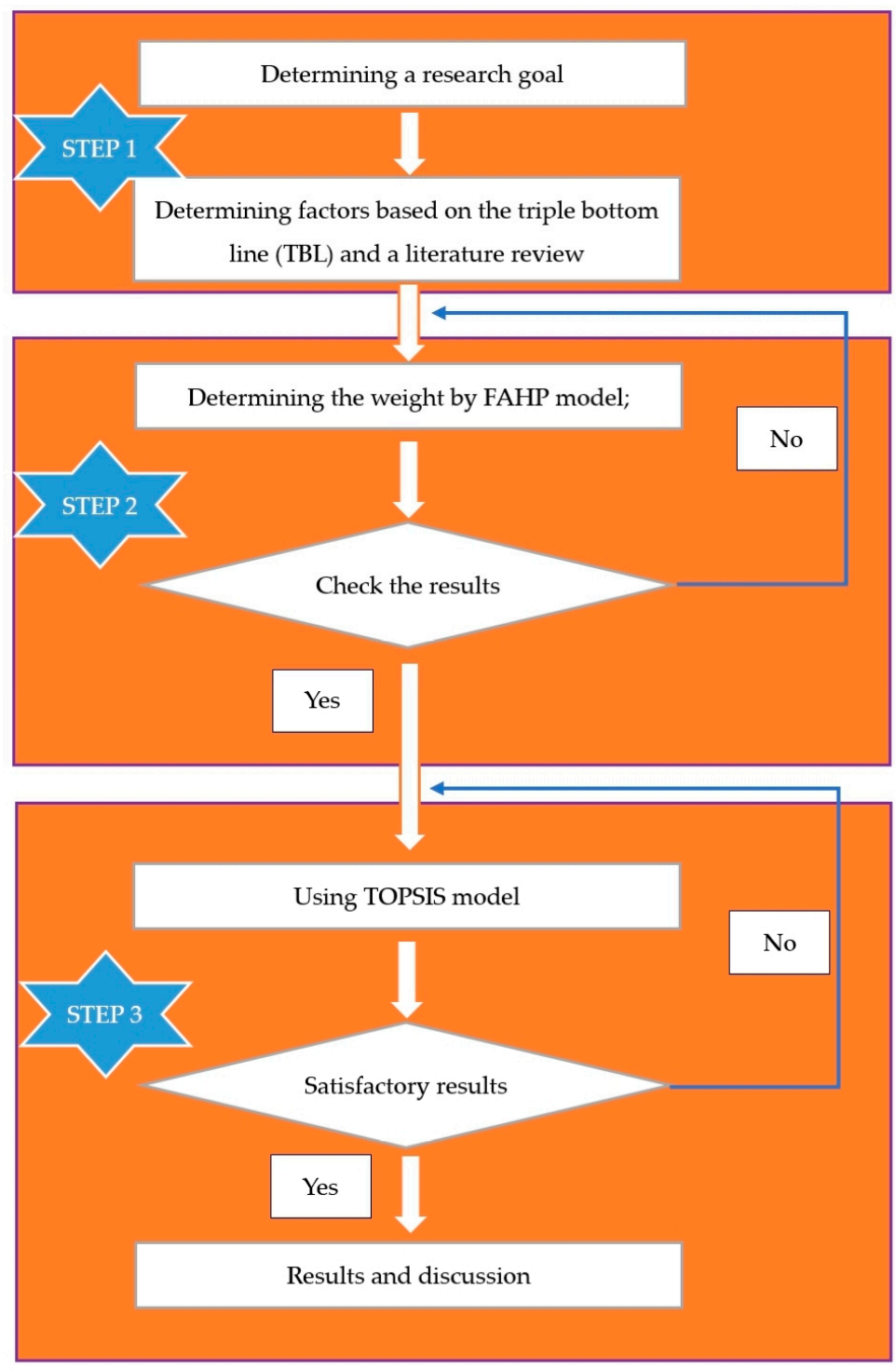

Figure 1. Research graph. FAHP—fuzzy analytic hierarchy process; TOPSIS—-technique for order of preference by similarity to an ideal solution. 


\subsection{Basic Model Theory}

\subsubsection{Multicriteria Decision-Making Model}

The MCDM model is an effective tool for solving complex selection problems, including qualitative and quantitative criteria with many alternatives. Qualitative criteria are often vague and difficult to identify accurately, thus making it difficult to synthesize assessment results according to criteria and decision making. The MCDM method quantifies these criteria, calculates the total scores of each decision-making unit (DMU), and helps decision-makers find an optimal alternative.

The evaluation of a supplier is also carried out on such qualitative criteria; thus, the MCDM model can be considered an effective tool for assessing suppliers. Nowadays, there have been many studies of MCDM applications in the green supplier selection model. Some commonly used methods are TOPSIS, AHP, ANP, FANP, FAHP, data envelopment analysis (DEA), and Fuzzy DEA.

Utilizing any decision-making technique involving the numerical analysis of alternatives requires three steps:

Step 1: Determine the relevant criteria and alternatives.

Step 2: Attach numerical measures to the relative importance of the criteria and to the impacts of the alternatives on these criteria.

Step 3: Process the numerical values to determine a ranking of each alternative.

\subsubsection{Triple Bottom Line (TBL)}

The concept of TBL is introduced by Elkington [21], who stressed the distinction between economic and social dimensions of sustainability, which have been absorbed by the environmental dimension of sustainability.

TBL is an accounting model with three parts: environment, economic, and social. Some organizations have adopted the TBL model to evaluate their performance in a broader perspective to create greater business value [22]. TBL, or the three pillars of sustainability approach, demonstrates the integration of all three aspects. The TBL graphic is shown in Figure 2.

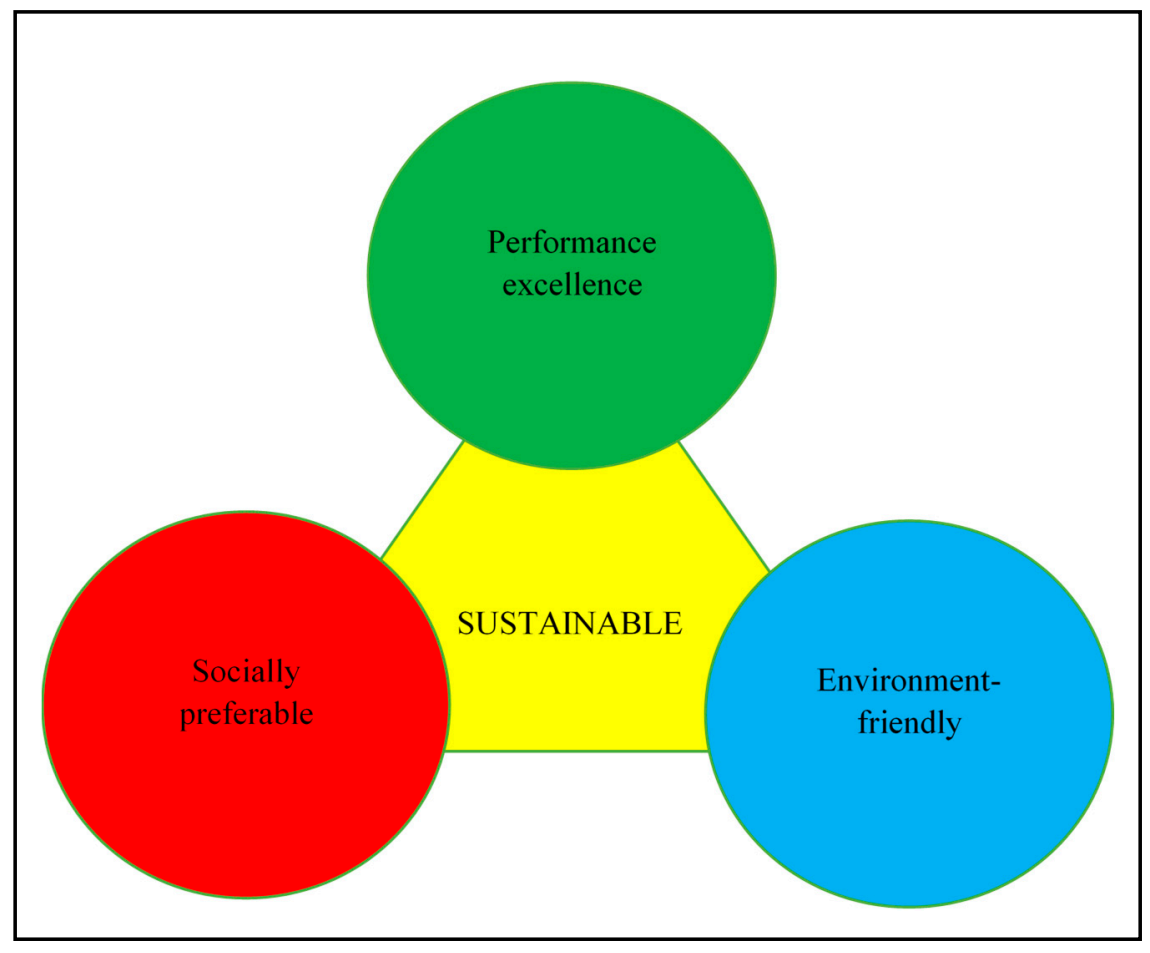

Figure 2. The triple bottom line (TBL) graphic [23]. 


\subsubsection{Fuzzy Sets and Fuzzy Number}

In 1965, Zadeh published the article with title "Fuzzy set", which describes the mathematics of "fuzzy set" and "fuzzy logic" theory. A triangular fuzzy number (TFN) can be defined as ( $k, f, h$ ). A TFN is shown in Figure 3.

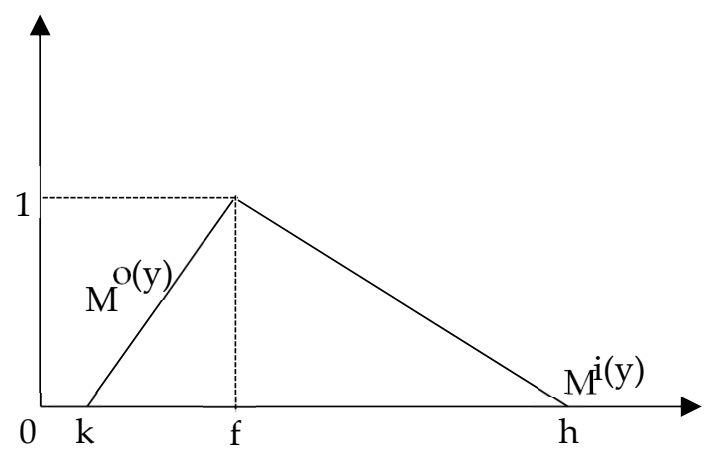

Figure 3. Triangular fuzzy number.

TFNs also can be defined as the following:

$$
\mu\left(\frac{x}{\widetilde{M}}\right)=\left\{\begin{array}{cc}
0, & x<o, \\
\frac{x-k}{f-k} & k \leq x \leq f, \\
\frac{h-x}{h-f} & f \leq x \leq h, \\
k . & x>h
\end{array}\right.
$$

The representatives of each level of membership for a given fuzzy number are the following:

$$
\widetilde{M}=\left(M^{o(y)}, M^{i(y)}\right)=[k+(f-k) y, h+(f-h) y], y \in[0,1]
$$

$o(y), i(y)$ indicates both the left side and the right side of a fuzzy number as:

$$
\begin{gathered}
\left(k_{1}, f_{1}, h_{1}\right)+\left(k_{2}, f_{2}, h_{2}\right)=\left(k_{1}+k_{2}, f_{1}+f_{2}, h_{1}+h_{2}\right) \\
\left(k_{1}, f_{1}, h_{1}\right)-\left(k_{2}, f_{2}, h_{2}\right)=\left(k_{1}-k_{2}, f_{1}-f_{2}, h_{1}-h_{2}\right) \\
\left(k_{1}, f_{1}, h_{1}\right) \times\left(k_{2}, f_{2}, h_{2}\right)=\left(k_{1} \times k_{2}, f_{1} \times f_{2}, h_{1} \times h_{2}\right) \\
\frac{\left(k_{1}, f_{1}, h_{1}\right)}{\left(k_{2}, f_{2}, h_{2}\right)}=\left(k_{1} / k_{2}, f_{1} / f_{2}, h_{1} / h_{2}\right)
\end{gathered}
$$

\subsubsection{Analytic Hierarchy Process (AHP) Model}

AHP is presented by Saaty; AHP is an MCDM that simplifies complex problems by sorting criteria and options in a hierarchical structure.

Let $F=\left\{F_{a} \mid a=1,2, \ldots, m\right\}$ be a factors set. The pairwise comparisons metrics on $\mathrm{m}$ criteria will be presented in an $\mathrm{m} \times \mathrm{m}$ evaluation matrix $D$; every element $h_{a b}$ is the quotient of weights of the factors:

$$
D=\left(h_{a b}\right), a, b=1, \ldots, m
$$

The relative priorities are given by the eigenvector (1), corresponding to the largest eigenvector $\left(\lambda_{\max }\right)$, as:

$$
D_{l}=\lambda_{\max } l
$$

The consistency is determined by the relation between the entries of $D$ and $C I$ :

$$
C I=\frac{\left(\lambda_{\max }-m\right)}{(m-1)}
$$


$C R$ is calculated as the ratio of $C I$ and $R I$, as shown in (7):

$$
C R=\frac{C I}{R I}
$$

$C R \leq 0.1$. If the $C R>0.1$, the evaluation needs to be repeated again to improve consistency.

\subsubsection{Technique for Order Preference by Similarity to an Ideal Solution (TOPSIS)}

The results of the analysis in some studies using the TOPSIS method shows that quality evaluation indicators affect the results of the evaluation, hence the selection of precise indicators is very important.

Determining TOPSIS requires performance ranking in every Ai option over every normalized $C_{j}$ factor. This can be seen from the formula below:

$$
e_{i j}=\frac{X_{i j}}{\sqrt{\sum_{i=1}^{m} X_{i j}^{2}}}
$$

with $i=1,2, \ldots, m$, and $j=1,2, \ldots, n$.

Calculate the normalized weighted decision matrix.

$$
S_{i j}=W_{i} e_{i j}
$$

with $i=1,2, \ldots, m$, and $j=1,2, \ldots, n$.

Calculate the PIS $A^{+}$matrix and NIS $A^{-}$matrix.

$$
\begin{aligned}
A^{+} & =s_{1}^{+}, s_{2}^{+}, \ldots, s_{n}^{+} \\
A^{-} & =s_{1}^{-}, s_{2}^{-}, \ldots, s_{n}^{-}
\end{aligned}
$$

Identify the gap between the values of each option with the positive ideal solution (PIS) matrix and negative ideal solution (NIS) matrix.

Options for PIS.

$$
D_{i}^{+}=\sqrt{\sum_{j=1}^{m}\left(s_{i}^{+}-s_{i j}\right)^{2}} ; i=1,2, \ldots, m
$$

Options for NIS.

$$
D_{i}^{-}=\sqrt{\sum_{j=1}^{m}\left(s_{i j}-s_{i}^{-}\right)^{2}} ; i=1,2, \ldots, m
$$

Calculate the preference value for every alternative $\left(G_{i}\right)$ :

$$
G_{i}=\frac{D_{i}^{-}}{D_{i}^{-}+D_{i}^{+}} \quad i=1,2, \ldots, m
$$

\section{Case Study}

In the current market economy, there is strong competition among businesses to be able to survive and develop sustainably in the market. Integration into the world economy has brought businesses many advantages, besides the typical disadvantages that enterprises face. To be able to compete with rivals, for example, requires businesses to constantly improve product quality, improve product samples to meet consumer demand, effectively use and manage resources such as capital, human resources, infrastructure, machinery, and equipment, and especially, achieve sustainability in garment business operations.

Sustainability is becoming a major target for the garment industry the world over as resources become more limited for development needs. Many companies actively monitor or measure the 
sustainability of the components and products they purchase. Thus, we propose an MCDM model for sustainable supplier evaluation and selection in the garment industry, based on the TBL approach.

The primary goal of this research is to propose a useful supplier selection process with sustainability development considerations based on economic, environmental, and social aspects. The proposed model is applied to rank potential fabric suppliers in the garment industry. After preliminary evaluations, 10 potential suppliers (DMUs) were selected.

The proposed model is applied to the Thi Hien Joint Garment Stock Company, which is among the leading enterprises in Vietnam's textile and garment industry. Since the establishment of the Thi Hien Garment Joint Stock Company, it has constantly improved its organizational structure, improved technology, and invested in modern equipment to bring the highest efficiency for work and improve product quality.

To enhance its competitive position in domestic and international markets, the enterprise itself is constantly evolving to improve supply chain management, and especially the sourcing of raw materials. Therefore, selecting suppliers of fabric materials is important and affects the company's business.

Based on the opinions of experts and the ability to provide raw materials, prices, and the ability to fulfill orders, 10 potential suppliers that typically bring high efficiency to the business are identified. A supplier list is shown in Table 1.

Table 1. The identification symbols of ten fabric suppliers.

\begin{tabular}{ccc}
\hline No & Supplier's Name & Symbol \\
\hline 1 & Kendor Textiles Ltd. & DMU/1 \\
2 & Gordon Fabrics LTD & DMU/2 \\
3 & Hangzhou New Design Source Textile Co., Ltd. & DMU/3 \\
4 & Shaoxing Charm Dress Co., Ltd. & DMU/4 \\
5 & Daechun Co., Ltd. & DMU/5 \\
6 & Seray Tekstil Sanayi Ve Ticaret Ltd., Sti & DMU/6 \\
7 & Ecopel (HX) Co., Ltd. & DMU/7 \\
8 & Nantong Haukai Textile Co., Ltd. & DMU/8 \\
9 & Taizhou City Longda Flax Textile Co., Ltd. & DMU/9 \\
10 & Zhejiang Haoyunlai Digital Textile Co., Ltd. & DMU/10 \\
\hline
\end{tabular}

All criteria affecting location selection were determined by a triple bottom line (TBL) model (economic, environmental, and social aspects) and literature reviews. The list of all criteria is shown in Table 2.

Table 2. List of all main and sub-criteria affecting sustainable fabric supplier selection.

\begin{tabular}{cc}
\hline Main Criteria & Sub-Criteria \\
\hline \multirow{2}{*}{ Economic } & Cost (EC1) \\
& Delivery reliability (EC2) \\
Quality (EC3) \\
Technology capabilities (EC4) \\
\hline Social & Employment practices (SO1) \\
& Health and safety (SO2) \\
& Local communities' influence (SO3) \\
& Contractual stakeholders' influence (SO4) \\
\hline Environmental & Pollution production (EV1) \\
& Resource consumption (EV2) \\
& Eco-design (EV3) \\
& Environmental management system (EV4) \\
\hline
\end{tabular}

The FAHP approach was utilized to identify the weight of all criteria. The authors set up a TFN. A pairwise comparison of the criteria was performed. Instead of a number value, the fuzzy analytical hierarchy process is a range of values that combine to evaluate criteria in this step. The fuzzy conversion scale is as shown in Table 3. 
Table 3. The fuzzy conversion scale.

\begin{tabular}{cc}
\hline Importance Intensity & Triangular Fuzzy Scale \\
\hline 1 & $(1,1,1)$ \\
2 & $(1,2,3)$ \\
3 & $(2,3,4)$ \\
4 & $(3,4,5)$ \\
5 & $(4,5,6)$ \\
6 & $(5,6,7)$ \\
7 & $(6,7,8)$ \\
8 & $(7,8,9)$ \\
9 & $(9,9,9)$ \\
\hline
\end{tabular}

A fuzzy comparison matrix for GOAL from the FAHP model is shown in Table 4.

Table 4. Fuzzy comparison matrices for GOAL.

\begin{tabular}{cccc}
\hline Criteria & EC & EV & SO \\
\hline EC & $(1,1,1)$ & $(3,4,5)$ & $(1,2,3)$ \\
EV & $(1 / 5,1 / 4,1 / 3)$ & $(1,1,1)$ & $(1,1,1)$ \\
SO & $1 / 2$ & $(1,1,1)$ & $(1,1,1)$ \\
\hline
\end{tabular}

The fuzzy numbers were converted to real numbers by using the TFN.

$$
\begin{gathered}
\mathrm{g}^{0.5,0.5}\left(\overline{a_{E C, E V}}\right)=[(0.5 \times 3.5)+(1-0.5) \times 4.5]=4 \\
\mathrm{f}_{0.5}\left(\mathrm{~L}_{\mathrm{EC}, \mathrm{EV}}\right)=(4-3) \times 0.5+3=3.5 \\
\mathrm{f}_{0.5}\left(\mathrm{U}_{\mathrm{EC}, \mathrm{EV}}\right)=5-(5-4) \times 0.5=4.5 \\
\mathrm{~g}^{0.5,0.5}\left(\overline{a_{E V, E C}}\right)=1 / 4
\end{gathered}
$$

The remaining calculations for other criteria are similar to the above calculation. The real number priorities when comparing the main criteria pairs are shown in Table 5.

Table 5. Real number priority.

\begin{tabular}{cccc}
\hline Criteria & EC & EV & SO \\
\hline EC & 1 & 4 & 2 \\
EV & $1 / 4$ & 1 & 1 \\
SO & $1 / 2$ & 1 & 1 \\
\hline
\end{tabular}

The maximum individual value is calculated as follows:

$$
\begin{gathered}
\mathrm{E} 1=(1 \times 4 \times 2)^{1 / 3}=2, \\
\mathrm{E} 2=(1 / 4 \times 1 \times 1)^{1 / 3}=0.62, \\
\mathrm{E} 3=(1 / 2 \times 1 \times 1)^{1 / 3}=0.79, \\
\sum \mathrm{E}=\mathrm{E} 1+\mathrm{E} 2+\mathrm{E} 3=3.41, \\
\omega_{1}=\frac{2}{3.41}=0.59, \\
\omega_{2}=\frac{0.62}{3.41}=0.18,
\end{gathered}
$$




$$
\begin{gathered}
\omega_{3}=\frac{0.79}{3.41}=0.23, \\
{\left[\begin{array}{ccc}
1 & 4 & 2 \\
1 / 4 & 1 & 1 \\
1 / 2 & 1 & 1
\end{array}\right] \times\left[\begin{array}{l}
0.59 \\
0.18 \\
0.23
\end{array}\right]=\left[\begin{array}{l}
1.77 \\
0.56 \\
0.71
\end{array}\right],} \\
{\left[\begin{array}{l}
1.77 \\
0.56 \\
0.71
\end{array}\right] /\left[\begin{array}{c}
0.59 \\
0.18 \\
0.23
\end{array}\right]=\left[\begin{array}{c}
3 \\
3.1 \\
3.1
\end{array}\right] .}
\end{gathered}
$$

Based on the number of main criteria, the authors get $n=4 ; \lambda_{\max }$ and $C I$ are calculated as follows:

$$
\begin{gathered}
\lambda_{\max }=\frac{3.0+3.1+3.1}{3}=3.01, \\
C I=\frac{\lambda_{\max }-n}{n-1}=\frac{3.01-3}{3-1}=0.05 .
\end{gathered}
$$

To calculate the $C R$ value, we get $R I=0.9$ with $n=4$.

$$
C R=\frac{C I}{R I}=\frac{0.05}{0.52}=0.0962
$$

Because $C R=0.0962 \leq 0.1$, we need not re-evaluate. The remaining values are calculated as the above calculation.

The weights of all of the criteria, defined by FAHP model, are shown in Table 6.

Table 6. The weights of all sub-criteria.

\begin{tabular}{cc}
\hline Sub-Criteria & Weight \\
\hline EC1 & 0.2125 \\
EC2 & 0.1802 \\
EC3 & $0 . .0868$ \\
EC4 & 0.1048 \\
SO1 & 0.0462 \\
SO2 & 0.0745 \\
SO3 & 0.0389 \\
SO4 & 0.0722 \\
EV1 & 0.0518 \\
EV2 & 0.0411 \\
EV3 & 0.0562 \\
EV4 & 0.0350 \\
\hline
\end{tabular}

A normalized matrix and normalized weight matrix were established from the TOPSIS model and are shown in Tables 7 and 8.

Table 7. Normalized matrix.

\begin{tabular}{ccccccccccc}
\hline & DMU/1 & DMU/2 & DMU/3 & DMU/4 & DMU/5 & DMU/6 & DMU/7 & DMU/8 & DMU/9 & DMU/10 \\
\hline EC1 & 0.2851 & 0.3258 & 0.3665 & 0.3665 & 0.2851 & 0.2443 & 0.3258 & 0.2851 & 0.3665 & 0.2851 \\
EC2 & 0.2782 & 0.3180 & 0.3180 & 0.2782 & 0.3180 & 0.3577 & 0.2385 & 0.3180 & 0.3577 & 0.3577 \\
EC3 & 0.2825 & 0.3229 & 0.3229 & 0.3229 & 0.3229 & 0.2825 & 0.3632 & 0.2825 & 0.2825 & 0.3632 \\
EC4 & 0.3269 & 0.2860 & 0.3269 & 0.3269 & 0.3677 & 0.3269 & 0.3269 & 0.2860 & 0.2452 & 0.3269 \\
SO1 & 0.2584 & 0.3015 & 0.3015 & 0.3446 & 0.3446 & 0.3015 & 0.3877 & 0.3015 & 0.3015 & 0.3015 \\
SO2 & 0.3269 & 0.3677 & 0.3269 & 0.2860 & 0.3677 & 0.2860 & 0.2860 & 0.2860 & 0.2860 & 0.3269 \\
SO3 & 0.3780 & 0.2940 & 0.3360 & 0.2940 & 0.2940 & 0.3360 & 0.2940 & 0.2940 & 0.3360 & 0.2940 \\
SO4 & 0.2860 & 0.3269 & 0.2860 & 0.2860 & 0.3677 & 0.2860 & 0.3269 & 0.2860 & 0.3269 & 0.3677 \\
EV1 & 0.3671 & 0.3263 & 0.3263 & 0.3263 & 0.3671 & 0.2855 & 0.3263 & 0.2855 & 0.2447 & 0.2855 \\
EV2 & 0.3052 & 0.3052 & 0.3052 & 0.3488 & 0.2616 & 0.3924 & 0.3052 & 0.3052 & 0.2616 & 0.3488 \\
EV3 & 0.3780 & 0.2940 & 0.3360 & 0.2940 & 0.2940 & 0.3360 & 0.2940 & 0.2940 & 0.3360 & 0.2940 \\
EV4 & 0.2860 & 0.3269 & 0.2860 & 0.2860 & 0.3677 & 0.2860 & 0.3269 & 0.2860 & 0.3269 & 0.3677 \\
\hline
\end{tabular}


Table 8. Normalized weight matrix.

\begin{tabular}{ccccccccccc}
\hline & DMU/1 & DMU/2 & DMU/3 & DMU/4 & DMU/5 & DMU/6 & DMU/7 & DMU/8 & DMU/9 & DMU/10 \\
\hline EC1 & 0.0261 & 0.0298 & 0.0336 & 0.0336 & 0.0261 & 0.0224 & 0.0298 & 0.0261 & 0.0336 & 0.0261 \\
EC2 & 0.0376 & 0.0430 & 0.0430 & 0.0376 & 0.0430 & 0.0484 & 0.0323 & 0.0430 & 0.0484 & 0.0484 \\
EC3 & 0.0472 & 0.0539 & 0.0539 & 0.0539 & 0.0539 & 0.0472 & 0.0607 & 0.0472 & 0.0472 & 0.0607 \\
EC4 & 0.0257 & 0.0225 & 0.0257 & 0.0257 & 0.0289 & 0.0257 & 0.0257 & 0.0225 & 0.0193 & 0.0257 \\
SO1 & 0.0230 & 0.0268 & 0.0268 & 0.0306 & 0.0306 & 0.0268 & 0.0345 & 0.0268 & 0.0268 & 0.0268 \\
SO2 & 0.0197 & 0.0221 & 0.0197 & 0.0172 & 0.0221 & 0.0172 & 0.0172 & 0.0172 & 0.0172 & 0.0197 \\
SO3 & 0.0367 & 0.0286 & 0.0327 & 0.0286 & 0.0286 & 0.0327 & 0.0286 & 0.0286 & 0.0327 & 0.0286 \\
SO4 & 0.0312 & 0.0357 & 0.0312 & 0.0312 & 0.0401 & 0.0312 & 0.0357 & 0.0312 & 0.0357 & 0.0401 \\
EV1 & 0.0395 & 0.0351 & 0.0351 & 0.0351 & 0.0395 & 0.0307 & 0.0351 & 0.0307 & 0.0263 & 0.0307 \\
EV2 & 0.0197 & 0.0197 & 0.0197 & 0.0225 & 0.0169 & 0.0254 & 0.0197 & 0.0197 & 0.0169 & 0.0225 \\
EV3 & 0.0212 & 0.0165 & 0.0189 & 0.0165 & 0.0165 & 0.0189 & 0.0165 & 0.0165 & 0.0189 & 0.0165 \\
EV4 & 0.0100 & 0.0114 & 0.0100 & 0.0100 & 0.0129 & 0.0100 & 0.0114 & 0.0100 & 0.0114 & 0.0129 \\
\hline
\end{tabular}

\section{Results and Discussion}

Besides raising public awareness of environmental issues and governmental regulations, supplier selection with sustainability considerations and segmentation has become a strategic issue for companies to gain and retain a competitive advantage in the global market. This study proposes a new integrated fuzzy MCDM model to select sustainable suppliers in the garment industry using sustainability considerations. The proposed approach combines the TBL, FAHP, and TOPSIS. The approach also allows the rating of alternatives and the importance weights of criteria for green supplier selection to be expressed in linguistic values. Finally, a case study is used to illustrate the computational procedure of the proposed approach. A TOPSIS model is applied in the final stage to rank all potential suppliers. TOPSIS is based on the concept that the chosen alternative should have the shortest geometric distance from the positive ideal solution (PIS) and the longest geometric distance from the negative ideal solution (NIS). Results are shows in Table 9 and Figure 4 (DMU/10 is the optimal fabric supplier in the garment industry).

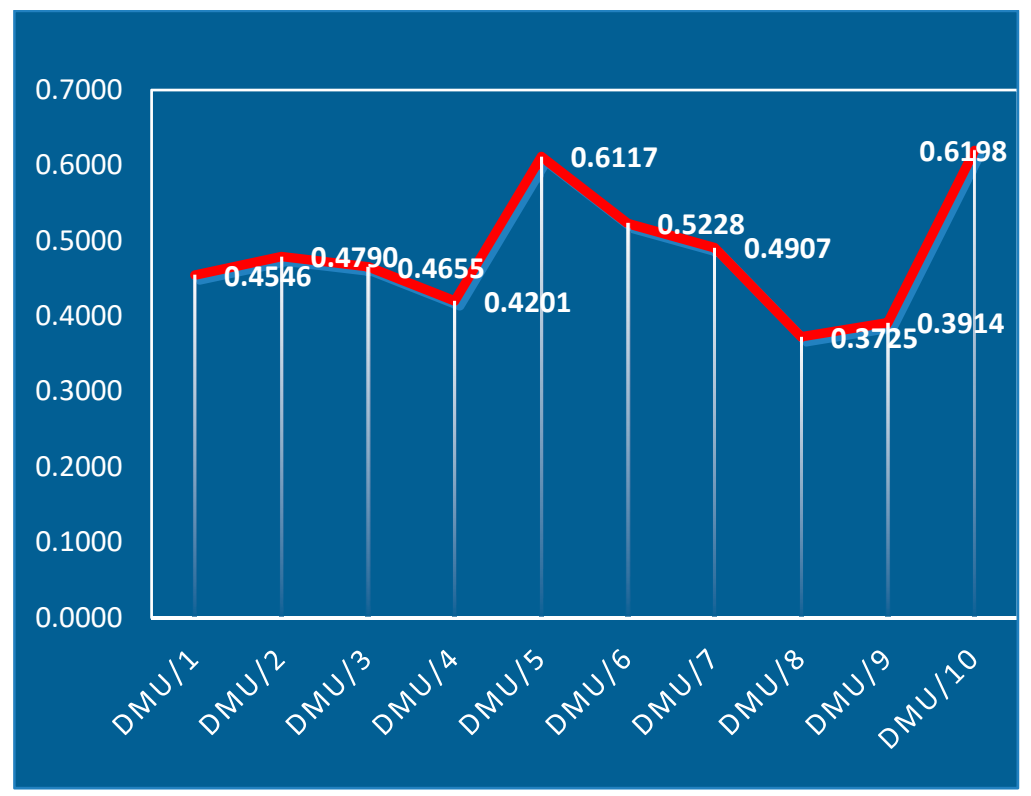

Figure 4. Final ranking score from the TOPSIS approach. 
Table 9. Negative ideal solution (NIS) and positive ideal solution (PIS) values.

\begin{tabular}{ccc}
\hline DMU & Di+ & Di- \\
\hline DMU/1 & 0.0241 & 0.0201 \\
DMU/2 & 0.0198 & 0.0182 \\
DMU/3 & 0.0209 & 0.0182 \\
DMU/4 & 0.0232 & 0.0168 \\
DMU/5 & 0.0162 & 0.0256 \\
DMU/6 & 0.0215 & 0.0235 \\
DMU/7 & 0.0226 & 0.0218 \\
DMU/8 & 0.0252 & 0.0150 \\
DMU/9 & 0.0278 & 0.0179 \\
DMU/10 & 0.0162 & 0.0264 \\
\hline
\end{tabular}

\section{Conclusions}

Along with growing awareness from the community in regard to environmental issues and government regulations, the selection and classification of sustainable suppliers has become a strategic business issue. This helps enterprises to win and maintain competitive advantages in the global market. The sustainable supplier selection process also plays an important role in sustainability development and contributes to the success of production businesses in the garment industry. Thus, many companies actively monitor or measure the sustainability of components and products they purchase. In order to select sustainable fabric suppliers, many economic, social, and environmental standards need to be considered in the assessment process. Therefore, the process of selecting a sustainable supplier can be considered as an MCDM.

Many researchers have applied the MCDM model to various fields of science and engineering, and more so over the last few years. One field in the MCDM approach in particular has identified optimal supplier selection problems; thus, notably in the garment industry, decision-makers have to evaluate both qualitative and quantitative criteria. Although some studies have reviewed applications of MCDM approaches in garment supplier selection, few works have focused on this problem in a fuzzy environment. This is why in this research, the authors proposed an MCDM model for supplier selection. In the first stage, all criteria affecting location selection are determined by a TBL model and literature reviews, and the FAHP approach was utilized to identify the weights of all criteria in the second stage. TOPSIS is used for ranking potential fabric suppliers in the final stage. As a result, decision-making unit 10 (DMU/10) is the best fabric supplier for the garment industry.

The contribution of this research includes modeling the supplier selection decision problem in the garment industry. The proposed model can also address different complex problems in supplier selection. In addition, it is a flexible design model for considering the evaluation criteria and is applicable to sustainable supplier selection in other industries.

Author Contributions: Conceptualization, C.-N.W., C.-Y.Y., and H.-C.C.; Formal analysis, H.-C.C.; Funding acquisition, C.-N.W.; Investigation, C.-Y.Y.; Methodology, C.-N.W., C.-Y.Y., and H.-C.C.; Project administration, C.-N.W. and C.-Y.Y.; Resources, H.-C.C.; Writing-original draft, H.-C.C.; Writing-review \& editing, C.-N.W. and C.-Y.Y.

Funding: This research received no external funding.

Conflicts of Interest: The authors declare no conflict of interest.

\section{References}

1. Minh, H. Hỗ Trợ Ngành Dệt May Phát Triển Bền Vững. Available online: http://www.sggp.org.vn/ho-tronganh-det-may-phat-trien-ben-vung-512818.html (accessed on 20 December 2018).

2. Aakko, M.; Koskennurmi-Sivonen, R. Designing Sustainable Fashion: Possibilities and Challenges. Res. J. Text. Appar. 2013, 7, 13-22. [CrossRef] 
3. Wang, C.-N.; Nguyen, V.T.; Thai, H.T.N.; Tran, N.N.; Tran, T.L.A. Sustainable Supplier Selection Process in Edible Oil Production by a Hybrid Fuzzy Analytical Hierarchy Process and Green Data Envelopment Analysis for the SMEs Food Processing Industry. Mathematics 2018, 6, 302. [CrossRef]

4. Western Cape Education Department (WCED). Our Common Future; Oxford University Press: Oxford, UK, 1987.

5. Rosen, M.A.; Kishawy, H.A. Sustainable Manufacturing and Design: Concepts, Practices and Needs. Sustainability 2012, 4, 154-174. [CrossRef]

6. Pavan, R.T.M. Multicriteria Decision-Making Methods. In Comprehensive Chemometrics; Elsevier: Amsterdam, The Netherlands, 2009.

7. Choi, T.-M.; Chiu, C.-H.; Govindan, K.; Yue, X. Sustainable fashion supply chain management: The European scenario. Eur. Manag. J. 2014, 32, 821-822. [CrossRef]

8. Baskaran, V.; Nachiappan, S.; Rahman, S. Indian textile suppliers' sustainability evaluation using the grey approach. Int. J. Prod. Econ. 2012, 135, 647-658. [CrossRef]

9. Lo, C.K.; Yeung, A.C.; Cheng, T. The impact of environmental management systems on financial performance in fashion and textiles industries. Int. J. Prod. Econ. 2012, 135, 561-567. [CrossRef]

10. Turker, D.; Altuntas, C. Sustainable supply chain management in the fast fashion industry: An analysis of corporate reports. Eur. Manag. J. 2014, 32, 837-849. [CrossRef]

11. Govindan, K.; Khodaverdi, R.; Jafarian, A. A fuzzy multi criteria approach for measuring sustainability. J. Clean. Prod. 2013, 43, 345-354. [CrossRef]

12. Wittstruck, D.; Teuteberg, F. Integrating the concept of sustainability into the partner selection process: A fuzzy-AHP-TOPSIS approach. Int. J. Logist. Syst. Manag. 2012, 12, 195-226. [CrossRef]

13. Büyüközkan, G.; Çifçi, G. A novel hybrid MCDM approach based on fuzzy DEMATEL, fuzzy ANP and fuzzy TOPSIS to evaluate green suppliers. Expert Syst. Appl. 2012, 39, 3000-3011. [CrossRef]

14. Kannan, D.; de Sousa Jabbour, A.B.L.; Jabbour, C.J.C. Selecting green suppliers based on GSCM practices: Using fuzzy TOPSIS applied to a Brazilian electronics company. Eur. J. Oper. Res. 2014, 233, $432-447$. [CrossRef]

15. Kannan, D.; Khodaverdi, R.; Olfat, L.; Jafarian, A.; Diaba, A. Integrated fuzzy multi criteria decision making method and multi-objective programming approach for supplier selection and order allocation in a green supply chain. J. Clean. Prod. 2013, 47, 355-367. [CrossRef]

16. Wang, X.; Chang, H.K. A hierarchical fuzzy TOPSIS approach to assess improvement areas when implementing green supply chain initiatives. Int. J. Prod. Res. 2013, 51, 3117-3130. [CrossRef]

17. Wang, Y.-J.; Lee, H.-S. Generalizing TOPSIS for fuzzy multiple-criteria group decision-making. Comput. Math. Appl. 2007, 53, 1762-1772. [CrossRef]

18. Mani, V.; Agrawal, R.; Sharma, V. Supplier selection using social sustainability: AHP based approach in India. Int. Strateg. Manag. Rev. 2014, 2, 98-112. [CrossRef]

19. Rouyendegh, B.D.; Erkan, T.E. Selecting the best supplier using analytic hierarchy process (AHP) method. Afr. J. Bus. Manag. 2012, 6, 1455-1462.

20. Grover, R.; Grover, R.; Rao, V.B.; Kejviwal, K. Supplier Selection Using Sustainable Criteria in Sustainable Supply Chain Management. Int. J. Econ. Manag. Eng. 2016, 10, 1775-1780.

21. Elkington, J. Cannibals with Forks: Triple Bottom Line of 21st Century Business; Capstone: Oxford, UK, 1999.

22. Slaper, T.F.P.; Hall, T.J. The Triple Bottom Line: What Is It and How Does It Work? Indiana Bus. Rev. 2011, $86,4-8$.

23. The Triple Bottom Line. BNAC Environmental Solutions Inc. Available online: http://bnac.ca/consumereducation/triple-bottom-line/ (accessed on 8 June 2019).

(C) 2019 by the authors. Licensee MDPI, Basel, Switzerland. This article is an open access article distributed under the terms and conditions of the Creative Commons Attribution (CC BY) license (http://creativecommons.org/licenses/by/4.0/). 